\title{
Percepção dos pais sobre a vivência da sexualidade de adolescentes com síndrome de Down
}

\author{
Cristina Portela da Mota, M.Sc.*, Ana Lúcia Motta de Carvalho**, Bianca Guimarães Pereira**
}

*Enfermeira, Doutoranda em Saúde Pública pela Escola Nacional de Saúde Pública Sérgio Arouca da Fundação Oswaldo Cruz, Professora Adjunta do Departamento de Enfermagem Materno-Infantil e Psiquiátrico da Universidade Federal Fluminense (MEP/UFF), **Enfermeira, graduada pela Escola de Enfermagem Aurora de Afonso Costa da Universidade Federal Fluminense $(E E A A C / U F F)$

\section{Resumo}

Estudo de abordagem qualitativa que objetivou conhecer a percepção dos pais sobre a vivência da sexualidade dos seus filhos adolescentes portadores da Síndrome de Down e a repercussão desta vivência para o cotidiano do próprio adolescente e da família. Foi realizado, em 2009, por meio de entrevistas semiestruturadas, gravadas, com onze mães e um pai de adolescentes com Síndrome de Down da Associação de Pais e Amigos dos Excepcionais (APAE) do Município de Niterói. Os depoimentos foram transcritos e analisados pelo método de interpretação de sentidos. Os resultados revelaram a importância de conhecermos valores, culturas e estilos de vida para compreendermos o universo da sexualidade dos adolescentes portadores da Síndrome de Down. A família, por sua vez, é importante para romper com o estigma e, assim, o portador desta síndrome pode vivenciar uma sexualidade saudável, pois ela é o lugar onde nos sentimos como parte de algo e aprendemos a nos relacionar, aceitar o outro e amar.

Palavras-chave: sexualidade, adolescentes, síndrome de Down.

\section{Abstract}

\section{Parents perception of the experience of sexuality in teenagers with Down syndrome}

This was a qualitative study that aimed to identify parents perception of the experience of sexuality in their children teenager with Down syndrome and the repercussion of this experience in everyday life of the adolescent and family. It was conducted in 2009 through semi-structured interviews, which were recorded, with eleven mothers and a father of teenagers with Down Syndrome Association of Parents and Friends of Exceptional Children (APAE) of Niterói city. After that the interviews were transcribed and analyzed by interpretation of meanings. The results revealed the importance of knowing values, cultures and lifestyles to understand the universe of sexuality of teenagers with Down syndrome. The 
family has an important role of breaking the stigma, so that teenagers with Down syndrome can experience healthy sexuality, because it is where we feel part of something and learn to relate, to love and to accept others.

Key-words: sexuality, adolescents, Down syndrome.

\section{Resumen}

\section{La percepción de los padres acerca de la vivencia de la sexualidad de adolescentes con síndrome de Down}

Estudio de enfoque cualitativo que tuvo como objetivo conocer las percepciones de los padres sobre la experiencia de sexualidad de sus hijos adolescentes con síndrome de Down y la repercusión de esta experiencia cotidiana de los adolescentes y la familia. Fue realizado, en 2009, por medio de entrevista semiestructurada, grabada con once madres y un padre de adolescentes con síndrome de Down de la Asociación de Padres y Amigos de Niños Excepcionales (APAE) del municipio de Niterói. Después, las entrevistas fueron transcritas y analizadas por el método de interpretación de sentidos. Los resultados revelaron la importancia de conocer los valores, culturas y estilos de vida para entender el universo de la sexualidad de los adolescentes con síndrome de Down. La familia juega un papel importante en romper con el estigma y, así, los adolescentes con este síndrome pueden experimentar una sexualidad saludable, pues es donde nos sentimos como parte de algo y aprendemos a relacionarnos, amar y aceptar a los demás.

Palabras-clave: sexualidad, adolescentes, Síndrome de Down.

\section{Introdução}

A sexualidade compreende uma categoria que transcende a biologia das estruturas corporais e dos processos fisiológicos, que materializam e objetivam o sexo a partir do determinismo biológico de se ter nascido homem ou mulher. Além disto, inclui as dimensóes biológicas, psicológicas, sociais, culturais e espirituais do indivíduo [1].

Em nossa sociedade, a sexualidade foi histórica e culturalmente limitada em suas possibilidades de vivência, devido a tabus, mitos, preconceitos, interdições e relaçóes de poder. $\mathrm{Na}$ adolescência esta se traduz em um campo de descobertas, experimentaçóes e vivência da liberdade, como, também, de construção da capacidade para a tomada de decisóes, de escolhas, de responsabilidades e de afirmaçáo de identidades, tanto pessoal como política [2]. Ainda, é o elemento significante na formação da identidade do adolescente e que se manifesta por múltiplas identificaçóes, tais como: a imagem corporal, a descoberta do outro como objeto de amor ou desejo e a descoberta de si e das relaçóes com os familiares, grupos e profissionais [3].

Observa-se que o adolescente descobre a sexualidade a partir da referência de colegas que estão nas ruas há mais tempo, assim como de experiências impostas por outros adolescentes ou adultos [4]. Essa fase da vida é frequentemente um período de desafio para o indivíduo e sua família, e esta se intensifica quando se é portador da Síndrome de
Down pelo fato que um corpo que não se encontra em plena ordem física e intelectualmente enfrentará as primeiras barreiras para interagir com o social, pois o adolescente terá de aprender a interagir com o mundo e começará a ter desejos de compreender o seu corpo, exprimindo sua sexualidade, além de se encarregar de inúmeras responsabilidades que chegam juntamente com esta fase da vida. E, ainda, terá de enfrentar os preconceitos da sociedade que acredita que uma pessoa "fisicamente diminuída" ou "intelectualmente retardada" não poderá responder a todas as solicitaçóes da formação sociocultural [5].

A Síndrome de Down é um distúrbio genético devido à presença adicional de um cromossomo 21 nas células de seu portador e que causa um retardo mental de variados graus. Os adolescentes portadores da Síndrome de Down não são indivíduos assexuados, e muito menos apresentam uma sexualidade incontrolada. Geralmente, surge o interesse pelo sexo oposto, tendo as mesmas necessidades afetivas e mesmo desejo sexual, na qual são capazes de fazer a escolha clara de uma pessoa para amar e manter relaçóes afetivas e sexuais estáveis. Contudo, isso ocorre de forma passiva e um tanto quanto infantilizada, sendo raro o efetivo relacionamento [6].

As mudanças hormonais se processam de forma semelhante às de adolescentes que náo tem a síndrome. Há pouca diferença na idade da menarca, que ocorre por volta de 12-13 anos e segue o padráo regular, mas podem acontecer ciclos anovu- 
latórios. No adolescente com Síndrome de Down, a genitália pode ser menor e menos desenvolvida, a ereção e ejaculação podem apresentar dificuldade e os espermatozóides podem ser menos numerosos e possuírem formas anormais $[7,8]$.

No que se refere aos aspectos comportamentais, historicamente, atribui-se a esses indivíduos características como: amabilidade, sociabilidade, obstinação, poder de imitação. A figura dócil e sociável dos portadores da Síndrome de Down, no entanto, não é uma coisa dada. Embora algumas características físicas dos portadores possam ser definidas pela síndrome e as características psicológicas são construídas no meio em que vivem [6].

O desempenho social do portador da Síndrome de Down é influenciado, em grande parte, pelo ambiente imediato ao seu redor. $\mathrm{O}$ resultado dessa interação pode restringir ou ampliar as oportunidades do seu desenvolvimento ou suas possibilidades de integração social $[9,10]$. Todos os valores culturais, estabelecidos pela forma de organização social, passam pelo indivíduo, através da unidade familiar. A formação da personalidade é, sem dúvida alguma, influenciada pela família que detém e faz circular em seu interior o reflexo do social maior e mais abrangente de toda a organizaçáo. Nesta medida, a educação dispensada na criação de um filho, vai ter necessariamente que passar pelos valores culturais que envolvem todos os habitantes desta formação sociocultural [11].

A família do adolescente portador da Síndrome de Down tem papel fundamental no seu desenvolvimento, não somente o pai e a mãe, mas todos os membros do núcleo familiar. É através das relações estabelecidas entre os seus membros, que se pode oferecer a esse adolescente um ambiente onde ele possa adquirir habilidades, aptidóes, conceitos e significados, em diversos aspectos do desenvolvimento da sua sexualidade. Esse saudável convívio irá proporcionar a ele as primeiras experiências afetivas e sexuais, que serão responsáveis pela formação de sua identidade. Além disto, "a família é vista como um sistema social responsável pela transmissão de valores, crenças, ideias e significados que estão presentes nas sociedades, que tem um impacto significativo e uma forte influência no comportamento dos indivíduos, especialmente dos jovens, que aprendem as diferentes formas de existir, de ver o mundo e construir as suas relaçóes sociais" [12]. O aparecimento de comportamentos sexuais em adolescentes que têm a síndrome costuma ser assustador para pais e cuidadores, pois as manifestaçóes que fazem parte do desenvolvimento saudável da sexualidade, como masturbação e namoro, podem ser recebidas com cautela e medo [13].

Neste sentido, viver uma sexualidade saudável e responsável na adolescência envolve promover a saúde dos adolescentes por meio da construção da consciência de autocuidado e cuidado com o outro. O cuidar da pessoa com deficiência, faz-se necessário uma equipe multiprofissional que tenha como pressuposto a globalidade do desenvolvimento das potencialidades dessa população [14]. Nessa equipe, a enfermagem, juntamente com outros membros, desenvolve um importante papel na promoção do autocuidado, tendo como função modificar o ambiente para aprendizagem e gerar comportamentos mais independentes, ajudando os portadores de deficiências a desenvolver seus talentos ao máximo e remover, quando possível, o preconceito que existe em relação a eles [12].

É imprescindível que o profissional de enfermagem reflita sobre seu papel e sua responsabilidade diante dos portadores de necessidades especiais, considerando que a educação em saúde é uma das alternativas que a enfermagem dispóe para transformar os sujeitos em indivíduos ativos na construção de sua vida e de sua independência, já que através da educação constroem-se cidadãos [15].

Diante do exposto, tem-se como objeto de estudo a percepção dos pais sobre a vivência da sexualidade dos seus filhos adolescentes portadores da Síndrome de Down. E, como questóes de pesquisa: como os pais percebem a vivência da sexualidade dos seus filhos portadores da Síndrome de Down? Quais as repercussóes desta vivência para o cotidiano do adolescente e da família? Para responder a estas questóes tem-se como objetivo conhecer a percepção dos pais sobre a vivência da sexualidade dos seus filhos adolescentes portadores da Síndrome de Down e a repercussão desta vivência para o cotidiano do próprio adolescente e da família.

\section{Material e métodos}

\section{Natureza do estudo}

Trata-se de uma pesquisa de abordagem qualitativa do tipo exploratório-descritiva.

\section{Local do estudo}

Foi desenvolvido na Associação de Pais e Amigos dos Excepcionais (APAE) do Município de Niterói, 
que é uma associação em que, além de pais e amigos dos excepcionais, toda a comunidade se une para prevenir e tratar a deficiência e promover o bem-estar e desenvolvimento da pessoa com deficiência.

\section{Participantes do estudo}

O estudo contou com a participação de onze máes e um pai de adolescentes portadores da Síndrome de Down de diferentes idades, raças e classes sociais. Dentre esses, seis deles eram casados, dois solteiros, dois viúvos e dois separados com idades entre 37 e 65 anos; ainda, oito residem no Município de Niterói e quatro no Município de São Gonçalo. Além disto, oito possuem o ensino fundamental incompleto, um possui o ensino fundamental completo, um o ensino médio completo, um com o ensino superior incompleto e um nunca estudou na vida.

Das mães entrevistadas, nove desenvolvem atividades no lar e duas trabalham fora de casa, porém sem carteira assinada, e o pai é aposentado. A maioria dos pais não trabalha fora de casa, pois precisam cuidar em tempo integral do filho portador da Síndrome de Down. Em relação à situação obstétrica, duas mães tiveram apenas uma gestação e nove eram multíparas. $\mathrm{O}$ número de filhos variou entre um e dez filhos e cinco das entrevistadas apresentaram história de aborto espontâneo.

\section{Procedimentos éticos}

O protocolo do projeto de pesquisa foi aprovado pelo Comitê de Ética em Pesquisa do Hospital Universitário Antônio Pedro (HUAP) sob o No 105/09. A escolha dos sujeitos ocorreu de maneira aleatória, sem qualquer tipo de distinção entre sexo, idade, raça e classe social, desde que conseguissem expressar-se verbalmente.

Primeiramente, fez-se uma aproximação com esses pais para obter sua confiabilidade, respeito e segurança, e, em seguida, convidamos cada um, por meio de carta-convite para participar da pesquisa. A correspondência continha uma descrição sucinta sobre os objetivos e a proposta do estudo, questóes referentes à identificaçáo da pesquisadora e da orientadora e sua disponibilidade para participar da pesquisa obedecendo aos preceitos éticos da pesquisa, conforme as Diretrizes e Normas Regulamentadoras de Pesquisa Envolvendo Seres Humanos - Resolução No 196/96 do Conselho Nacional de Saúde.
O segundo contato foi a entrevista propriamente dita, realizada na sala de atendimento social aos pais situada no $1^{\circ}$ andar da Associação de Pais e Amigos dos Excepcionais (APAE) do Município de Niterói.

\section{Procedimentos para a coleta de dados}

O instrumento de coletas dos dados utilizado foi a entrevista semiestruturada com perguntas abertas e fechadas, constituído de duas partes; a primeira, contendo dados de caracterizaçáo socioeconômica da família, e a segunda, dados relacionados com a percepção dos pais sobre a vivência da sexualidade dos seus filhos adolescentes portadores da Síndrome de Down e a repercussão desta vivência para o cotidiano do próprio adolescente e da família.

Nesta investigação, as entrevistas foram gravadas em mp3 e imediatamente transcritas pelos pesquisadores. As transcriçôes imediatas das entrevistas permitiram organizar as ideias em relação aos questionamentos.

Foram escolhidos codinomes de flores para os pais, porque esses nomes representam a força, a coragem, a simplicidade e o otimismo desses pais pela vida de seus filhos, garantido assim, o sigilo e o anonimato dos depoimentos.

\section{Resultados e discussão}

Em termos de procedimento analítico adotado neste estudo, utilizou-se o método de interpretação de sentidos, baseando-se em princípios da hermenêutica-dialética para a interpretaçáo das entrevistas. A hermenêutica é a busca da compreensão de sentido que se dá na comunicação entre seres humanos, tendo a linguagem seu núcleo central e a dialética é a ciência e a arte do diálogo, da pergunta e da controvérsia [16]. A trajetória analítico-interpretativa percorreu os seguintes passos (que, necessariamente, náo são excludentes mutuamente e nem sequenciais): a) leitura compreensiva, visando impregnaçáo, visão de conjunto e apreensão das particularidades do conjunto do material gerado por esta pesquisa; b) recorte dos depoimentos acerca da percepção dos pais sobre a vivência da sexualidade dos seus filhos adolescentes portadores da Síndrome de Down; c) identificação das ideias implícitas ao texto; d) problematização das ideias em termos de diferenças e pontos comuns dos depoimentos; e) busca de sentidos mais amplos que articulam modelos subjacentes 
às ideias; f) diálogo entre as ideias problematizadas, informaçóes provenientes de outros estudos acerca do assunto e a revisão de literatura do estudo; e g) elaboração de síntese interpretativa, procurando articular objetivo do estudo e dados empíricos.

Ao concluir as entrevistas consentidas pelos pais dos adolescentes portadores da Síndrome de Down, percebeu-se o quanto esse estudo foi intermediado por grandes emoçóes e desafios. Duas categorias emergiram da pesquisa: Síndrome de Down e o Adolescente: aprendendo a vivenciar a sexualidade como fonte de vida; e, a arte do cuidado voltado para a sexualidade de adolescentes com Síndrome de Down.

\section{Síndrome de Down e o adolescente: aprendendo a vivenciar a sexualidade como fonte de vida}

Desde o nascimento a criança inicia o processo de independência em relação aos pais continuando e acelerando na fase da adolescência. Fascinado e assustado com as mudanças em nível físico e emocional o adolescente tem dificuldade em comunicar suas preocupações aos pais que, por sua vez, têm dificuldade de entender e aceitar o despertar da sexualidade neste momento. Essa questáo se intensifica quando se trata de um adolescente que tem a Síndrome de Down.

Ao iniciar as entrevistas com os pais dos adolescentes com Síndrome de Down, foi possível perceber uma grande dificuldade destes em definir sexualidade, conforme evidenciado nos relatos, a seguir:

"É desejo, uma coisa mais carnal." (Margarida)

"Eu entendo que é uma coisa da natureza, boa e sadia. É de onde vêm os frutos. (...) Minha filha desenvolveu a relação com 16 anos e se casou com 17.” (Rosa)

"É o despertar dos hormônios; as coisas que se vê que é ouvida e que é ensinada” (Lírio)

"É um relacionamento afetivo, uma parceria, companheirismo." (Camélia)

A sexualidade é definida como o resultado de uma construção histórica, refletindo os valores e a moral de cada sociedade, num determinado período de tempo, compreendendo as dimensóes biológica, psicológica e cultural, imbricadas ou dissociadas. Portanto, a sexualidade é vista como uma construção social e baseia-se na coordenação de uma atividade mental e corporal, que são aprendidas pela cultura [17].

Ao se abordar a questáo da sexualidade humana no período da adolescência, ela trouxe consigo aspectos importantes da sexualidade tais como: masturbação, beijos e carícias, conforme observamos nos depoimentos abaixos:

"Já está sem vergonha. Quando vê uma menininha quer abraçar, quer beijar, fica olhando (...)" (Sempre viva)

"Ela tem os bonecos da Mônica e fica se esfregando em cima dos bichinhos antes da menstruação e depois." (Rosa)

“(...) Ele fala que quer ir dormir porque quer ir para o quarto, depois pede um short, aí já sei que ele se masturbou (...)" (Copo de Leite)

A masturbação na adolescência não serve apenas para satisfazer o desejo, ou aliviar a tensão sexual, mas também fornece um meio seguro de experimentação sexual, aumenta a autoconfiança sexual, controla os impulsos sexuais, combate a solidão e descarga as tensôes e o estresse geral [18].

Vivemos em uma era de liberdade de expressão e de um estilo livre de vida. Hoje vemos nos filmes, nas novelas, nas músicas, nas danças e nas roupas da moda uma comercialização do sexo. Levando em consideração o papel da mídia na questão da sexualidade na adolescência; temas, conteúdos e comportamentos antes restritos aos adultos são hoje vistos tanto pelas crianças quanto pelos adolescentes:

"Eu percebo a manifestação sexual da minha filha, quando ela assiste televisão. Quando ela vê um ator que ela gosta e diz: hum... olha lá mamãe, gostoso.” (Rosa)

"Ela olha na televisão as pessoas beijando e quer beijar também”. (Flor do Campo)

"Ela fala para a televisão: - safada, olha lá pai." (Dália)

Os adolescentes estão, cada vez mais, ao abrigo dos efeitos da mídia. A busca de modelos externos, tí- 
pica desta fase de separaçáo dos modelos familiares, faz com que aqueles carentes de referências que suportem esta passagem tomem os padróes e comportamentos sexuais que a mídia exibe como regra de conduta.

Se considerarmos que a mídia, hoje, é responsável por um imenso volume de trocas simbólicas e materiais em dimensóes globais, abre-se para a educação um novo conjunto de problemas, numa dinâmica social que exige não só medidas urgentes por parte das políticas públicas educacionais, mas igualmente uma reflexão mais acurada sobre as relaçôes entre educação e cultura [19].

A sexualidade é uma das forças fundamentais da vida humana que penetra toda a existência individual e social. Por esta razão, a sexualidade, a religiáo, a fé, a ideologia e a ética se entrelaçam, conforme evidencia o relato de Girassol, uma mãe de 52 anos de idade, desquitada e residente do Município de São Gonçalo:

"Bom antigamente, falar de sexualidade era mais respeitado. Uma coisa conservadora, que tem haver com a religião. Hoje é uma bagunça.” (Girassol)

Nos comportamentos sexuais dos indivíduos, as práticas, os relacionamentos e os significados estão enraizados no conjunto das experiências que constituem as pessoas como seres sociais, dentro dos cenários culturais da sexualidade dominante em suas respectivas sociedades. Diversos fatores contribuem para modelar essas experiências da sexualidade de maneira diferenciada de acordo com os grupos sociais, religiosidade, condiçóes de vida, redes de sociabilidade, padróes de relaçáo entre os sexos, usos do corpo e posição na estrutura social, além das experiências vivenciadas ao longo do curso de vida [20].

Portanto, qualquer pessoa independentemente de sua condição físico-mental não só pode, mas deve ser considerada como uma pessoa plena de direitos às possibilidades de desenvolvimentos que a vida oferece, incluindo, as possibilidades sexuais de cada ser. $\mathrm{O}$ que precisamos perceber, no que tange à sexualidade humana, é que esta não se refere ao contato físico somente e propriamente dito, mas envolve a amizade, o carinho, a aprovação e as relaçóes pessoais.

\section{A arte do cuidado voltado para a sexualidade de adolescentes com Síndrome de Down}

O cuidar é uma prática inerente ao ser humano e dispensado aos filhos é seguramente o mais sig- nificativo. Quando um pai tem a seu cuidado um filho adolescente portador de Síndrome de Down o ato de cuidar exige do cuidador uma atenção redobrada. Ao cumprir seu papel, os pais testemunham momentos de transformação na vida de seus filhos, principalmente no período da adolescência, quando profundas mudanças físicas, psíquico e social acontecem. Esses períodos são ricos e deixam entrever manifestações de desejos que afloram naturalmente. Não é diferente com os deficientes, conforme constatamos nos relatos abaixo:

"Ela tem um amigo e já pegamos eles se
beijando. Quando eles foram lá em casa
pegamos um em cima do outro. Tenho que
ficar o tempo todo de olho nela." (Rosa)
"Ele já falou que quer crescer para namorar."
(Margarida)

"Ele tem um fogo danado. Só pensa em namorar". (Camélia)

"Ele tem uma amiguinha que ele fala que é
namorada. E ela fala também que é namo-
rada dele." (Tulipa)

Especialistas de diferentes áreas do conhecimento acreditam que, dependendo do grau de compreensão, os adolescentes com Síndrome de Down podem aprender a lidar com a sexualidade e a nutrir relaçóes afetivas e sexuais saudáveis [7]. Desta forma, os profissionais de saúde e da educação que trabalham com adolescentes portadores da Síndrome de Down têm um papel fundamental na orientaçáo sexual desses adolescentes e seus familiares, proporcionando um cuidado mais integral e humanizado.

A arte de cuidar é a atividade humana por excelência, pois surge no seio da relação dialógica inter-humana, faz do homem aquilo que ele é. O ciclo do cuidado percorre toda a nossa existência, somos cuidados, cuidamo-nos e zelamos pelo cuidado do outro. Para além de ser uma atividade eminentemente humana transmitida através da cultura e educação, também, é uma profissão [21]. É fundamental para a enfermagem atuar na área da reabilitação, assistir as famílias e trabalhar com educadores e colaboradores da APAE, pois eles exercem um papel importante na prevenção de agravos à saúde e na promoção do autocuidado aos portadores de necessidades especiais. 
Nas últimas décadas, a melhora dos cuidados de saúde e o avanço social que as pessoas com Síndrome de Down vêm alcançando, têm sido muito positiva e por meio do processo de inclusão social, os adolescentes com Síndrome de Down são capazes de viver integrados na sociedade e, portanto, expostos a riscos, liberdades e responsabilidades. $\mathrm{O}$ relacionamento entre pais e filhos com Síndrome de Down é de extrema relevância para a formação da identidade humana. Poucos estudos, no entanto, falam sobre essa interação. É importante considerar o deficiente como parte integrante das relaçóes familiares. Ter consciência dessa relação é, portanto, condição necessária para compreender a vida do adolescente. Durante a realização das entrevistas, no entanto, apenas um pai esteve presente. $\mathrm{O}$ relato de José, um senhor de 65 anos, casado e aposentado, evidencia a participação constante que deve haver do pai na vida do filho:

"Procuro estar sempre presente no cuidado do meu filho, inclusive, porque ele tinha uma certa agressividade. Uma vez ele beliscou uma colega de sala, como se fosse uma autodefesa, mas a professora deu um conserto nele."

Ser pai é fácil, na verdade, nós homens assim nos tornamos quando o bebê nasce. No entanto, alimentar o desejo de o ser, preparar-se para o ser e tornar-se pai é difícil. Pois pai não é quem o gera, é quem o cuida, quem o abraça, quem lhe dá amor, quem participa junto da mãe em sua criação, felicidade, saúde e doença. Ser pai é tentar ser mãe e o sê-lo, mesmo que esse significado só seja percebido dentro dele mesmo [22].

A pouca participaçáo do pai na vida dos filhos com Síndrome de Down, de certa forma, começa quando ele recebe o diagnóstico de que seu filho nasceu com a Síndrome de Down:

"A minha família está acostumada com ela. Da parte do pai ele náo quis nem saber. É difícil um casal com criança especial se dar bem." (Girassol)

Os homens continuam se representando e sendo representados por papéis fora do centro das interaçóes familiares, o que pode ser justificado pelas pressóes do trabalho, pela falta relativa de recompensa por seu engajamento nos cuidados das crianças e pelas sutis negociaçóes entre os parceiros sobre a parte a ser desempenhada pelo homem na família [23].

Contrariando a literatura em geral, que aponta que os pais consideram seus filhos como assexuados e ingênuos, os depoimentos colhidos na pesquisa indicam uma relação afetiva e sexual satisfatória com os filhos:

\footnotetext{
"Eu aceito, concordo. Faria um casamento com todo prazer, porque eu senti que ela sente o que eu sentia e o que os meus filhos sentem não tem coisa melhor que amar" (Rosa)
}

"Não ponho obstáculo não, só não aconselharia a ter filhos porque não sei quanto tempo vou viver. Quem vai cuidar da criança?.” (Dália)

"Iria achar legal ele ter um relacionamento afetivo e sexual, para ele ter um prazer a mais." (Margarida)

As necessidades e os comportamentos sexuais dos adolescentes podem ser assustadores para os pais e outros familiares. À medida que as mudanças físicas são muito acentuadas, a sexualidade pode ter uma expressão que pode parecer exagerada. $\mathrm{O}$ desenrolar da situação está ligado à sexualidade das pessoas envolvidas. Ou seja, pais que estão à vontade com sua sexualidade conseguem aceitar melhor a sexualidade dos filhos e filhas e transmitem-lhes essa aceitação. Por outro lado, se a sexualidade é negada, ignorada ou rejeitada pelos pais, as possibilidades de desenvolvimento de um autoconceito sexual positivo ficam diminuídas e isto pode se expressar como alienação, atividade sexual prematura ou excessiva [24].

A família exerce um papel essencial na interação social do seu filho e vem a ser uma importante instituição na formação de valores morais, espirituais e éticos. O núcleo familiar é, em última instância, o responsável pela formação de padróes de comportamento. É a partir dos seus familiares que a criança é inserida no mundo, cabendo aos pais oferecer condiçóes para que elas possam se desenvolver e é na adolescência que a família deve preparar o adolescente para a vida adulta, proporcionando-lhe maior independência e autonomia [25].

O comportamento sexual de um indivíduo depende não só da etapa de desenvolvimento em 
que se encontra, mas também do contexto familiar e social em que vive. Questionamos aos pais dos adolescentes com Síndrome de Down se e como o relacionamento afetivo e sexual repercutia no cotidiano da sua família. Os entrevistados relataram que a repercussão é positiva no ambiente familiar:

"São todos a favor. Ela veio depois de onze anos de ligadura. Em casa é como se fosse um troféu. Ela conquista a todos. A família apóia tudo dela." (Rosa)

"A família ia gostar, tem muito chamego. Tudo o que ele faz é bom. Seria muito bom que ele tivesse uma relaçáo afetiva, eu estaria com ele, pois é meu filho." (Camélia)

"É bom, todo mundo fica feliz de ver o relacionamento amoroso dele." (Tulipa)

A puberdade e a maturação sexual de pessoas com Síndrome de Down se desenvolvem de forma semelhante ao restante da populaçáo, embora, a fertilidade em homens com Síndrome de Down seja, em geral, mais reduzida que em mulheres com a mesma síndrome. Tendo em vista essas informaçóes é possível esperar que o início do interesse sexual incluindo o desejo de namorar, de aproximar-se do outro, a preocupaçáo com a aparência, a curiosidade por assuntos relacionados - surja em época semelhante a dos demais adolescentes [24].

Parte das dificuldades dos pais e profissionais em lidar com aspectos relacionados à sexualidade de adolescentes com Síndrome de Down advém da quantidade incipiente de conhecimento sobre esses aspectos. Essa lacuna deve ser preenchida, porque é grande a demanda por informaçóes de todos aqueles que lidam ou trabalham com essas pessoas.

\section{Conclusão}

A sexualidade é diferente a cada fase do desenvolvimento humano. Os adolescentes com Síndrome de Down são seres sexuados e, a cada estágio da vida, possuem interesses sexuais específicos e os exprimem por meio de comportamentos da própria sexualidade.

A discussão da sexualidade em nossa cultura, tradicionalmente, vem acompanhada de preconceito e discriminação. Quando o assunto passa a ser sexualidade no adolescente portador da Síndrome de
Down, o preconceito e a discriminação são intensificados e geram polêmica quanto às diferentes formas de abordá-lo, tanto com os próprios adolescentes, quanto com suas famílias e na escola.

A sexualidade é uma função natural, existente em todas as pessoas e pode ser expressa no seu componente afetivo, erótico ou afetivo-erótico. Ela provoca grande angústia e ansiedade nas famílias e as primeiras manifestaçóes são vistas com surpresa e medo, decorrentes de ideias que a colocam como imprevisível e incontrolável.

$\mathrm{Na}$ verdade, os pais têm que encarar o fato que, mesmo sendo um adolescente com Síndrome de Down, o corpo começa a se modificar e é importante que os pais acompanhem essa transformação. O desejo de namorar, a masturbaçáo e os jogos sexuais relatados pelos pais dos adolescentes com Síndrome de Down são comuns nesta fase da vida e o conhecimento corporal, a expressão da afetividade e a exploração de diferentes sensaçôes e prazeres são fundamentais para desenvolvimento da sexualidade humana.

Diante de tais constataçôes, acreditamos que o adolescente com Síndrome de Down seja capaz de ter um relacionamento afetivo e sexual saudável, à medida que ele é preparado para tal. Sendo fundamental, assim, que as expressóes sexuais desse adolescente não sejam reprimidas, ao contrário, devemos ensiná-los quando e aonde eles podem se expressar.

\section{Referências}

1. Trindade WR, Ferreira MA. Sexualidade feminina: questóes do cotidiano das mulheres. Texto Contexto Enferm 2008;17(3):417-26.

2. Brasil. Ministério da Saúde. Secretaria de Atenção à Saúde. Departamento de Açóes Programáticas Estratégicas. Marco teórico e referencial: saúde sexual e saúde reprodutiva de adolescentes e jovens/ Ministério da Saúde, Secretaria de Atenção à Saúde, Departamento de Açôes Programáticas Estratégicas. Brasília: Ministério da Saúde; 2006.

3. Romero KT. O conhecimento das adolescentes sobre questóes relacionadas ao sexo. Rev Assoc Med Bras 2007;53(1):14-9.

4. Medeiros M, Ferriani MGC, Munari DB, Gomes R. A sexualidade para o adolescente em situação de rua em Goiânia. Rev Latinoam Enferm 2001;9(2):35-41.

5. Casarin S. Síndrome de Down: caminhos da vida [Tese]. São Paulo: Pontifícia Universidade Católica de São Paulo; 2007.

6. Almeida MSR. A expressão da sexualidade das pessoas com Síndrome de Down. São Paulo: Instituto Inclusão Brasil; 2008.

7. Gonçalves ACM, Moya CI. Sexualidade e o adolescente portador de Síndrome de Down. In: X Encontro Latino 
Americano de Iniciação Científica e VI Encontro Latino Americano de Pós-Graduação - Universidade do Vale do Paraíba. São José dos Campos: Univap; 2006.

8. Trumble S. How to treat people with Down Syndrome: some tips for family physicians. Department of Community Medicine, Monash University, Australia; 1995.

9. Chevallier E. A importância do trabalho sobre as representaçóes na formação dos agentes sanitários e sociais. Rev Bras Crescimento Desenvol Hum 1993;3(1):160-62.

10. Ribas JB. O que são pessoas deficientes? São Paulo: Brasiliense; 2003.

11. Van Dyke DC, Mcbrien D, Sherbondy A. Issues of sexuality in Down syndrome. Down Syndrome Research and Practice 1995;3(2).

12. Kreppner K. The child and the family: Interdependence in developmental pathways. Psic Teor Pesq 2000;16(1):11-22.

13. Blascovi-Assis SM. Lazer e deficiência mental: o papel da família e da escola em uma proposta de educação pelo e para o lazer. Sáo Paulo: Papirus; 1997.

14. Carswell WA. Estatuto da assistência de enfermagem a crianças que apresentam Síndrome de Down. Rev Latinoam Enferm 1993;2(1):97-112.

15. Silva AMF. Refletindo sobre a qualidade de vida do portador de deficiência: resgatando os direitos de cidadão. Texto e Contexto Enferm 1999;8(3):88-98.

16. Minayo MCS. Hermenêutica-dialética como caminho do pensamento social, próprio. In: MCS Minayo
\& SF Deslandes (orgs.). Caminhos do pensamento: epistemologia e método. Rio de Janeiro: Fiocruz; 2002.

17. Melo ASAF, Santana JSS. Sexualidade: concepções, valores e condutas entre universitários de Biologia da UEFS. Rev Baiana Saúde Pública 2005;29(2):149-59.

18. López F, Fuertes A. Para entender a sexualidade. Traduzido por: Gonçalvez MS \& Sobral AU. Sáo Paulo: Loyola; 1992.

19. Fischer R. Identidade, cultura e mídia: a complexidade de novas questóes educacionais na contemporaneidade. In: Silva LH, ed. Século XXI: qual conhecimento? Qual currículo? Petrópolis: Vozes; 1999b. p.18-32.

20. Bozon M. Sociologia da sexualidade. Rio de Janeiro: FGV; 2004.

21. Fragoso V. A arte de cuidar e ser cuidado: cuidar-se para cuidar. IGT na Rede 2008;3(5).

22. Moulin IC. A mudança da minha vida: Ser pai. [citado 2010 Dez 12]. Disponível em URL: www.reflexóes. diarias.nom.br.

23. Henn CG, Piccinini CA, Garcias GL. A família no contexto da Síndrome de Down: revisando a literatura. Psicol Estud 2008;13(3):485-93.

24. Preto NG. Família-função de sistema de apoio emocional: transformação do sistema familiar na adolescência. In: McGoldrick M, Carter B, eds. As mudanças no ciclo de vida familiar: uma estrutura para a terapia familiar. Porto Alegre: Artes Médicas; 1995. p.223-47.

25. Moreira LMA, Gusmão FAF. Aspectos genéticos e sociais da sexualidade em pessoas com Síndrome de Down. Rev Bras Psiquiatr 2002;24(2):94-9. 